\title{
Left ventricular opacification after peripheral venous injection of a modified albumin solution
}

Shoa-Lin Lin, Jin-Hsiang Lo, ${ }^{1}$, Chung-Yuan Mou, ${ }^{1}$ Shuenn-Jiin Ho, ${ }^{2}$ Ren-Hon Liu, ${ }^{3}$ Julie Y.H. Chan, ${ }^{3}$ Mau-Song Chang, ${ }^{2}$ Hung-Ting Chiang \& Chung-Yin Chen

From the Division of Cardiology, Department of Internal Medicine, Veterans General Hospital-Koahsiung and ${ }^{2}$ Taipei, ${ }^{3}$ Department of Medical Research, National Yang-Ming Medical College and

${ }^{1}$ Department of Chemistry, National Taiwan University, Taiwan, Republic of China

Accepted 16 November 1991

Key words: echocardiography, contrast agent, contrast echocardiography

\begin{abstract}
The usefulness of a modified albumin solution was assessed in 8 dogs after peripheral venous and inferior vena cava injections. The contrast agent is a mixed solution made of glucose, albumin and glycerin, with sonicated microbubble diameter of $5.0 \pm 2.3 \mu \mathrm{m}$. Multiple injections ( $8 \mathrm{ml}$ each) of this contrast agent (total 80 injections) into peripheral vein and inferior cava were performed. The blood pressure from femoral artery was measured before, during and after injections.

Two-dimensional echocardiograms were recorded in a modified long axis view on videotapes for play back analysis. The pulmonary transit time and left ventricular contrast persistent time was determined for each injection. The videodensity of the region of interest (ROI) at the center of right ventricle and left ventricle was measured. The background videodensity of both ventricles was evaluated. The videodensity over the ROI of both ventricles with peak contrast enhancement was measured in all frames for 3 consecutive cardiac cycles. The peak videodensity of right and left ventricle subtracting the background videodensity of each ventricles was further calculated respectively.

The injections caused no change in blood pressure or heart rate. All injections produced right ventricular contrast echo. As much as $85 \%$ of peripheral venous and $82.5 \%$ of inferior vena cava injections resulted in left ventricular contrast which was 0.68 and 0.65 as bright as that produced in the right ventricle. Pulmonary transit time and left ventricle contrast persistent time of peripheral venous injection was $4.05 \pm 0.53$ and $13.67 \pm 4.28$ seconds respectively. No difference of these data $(3.93 \pm 0.47$ and $11.65 \pm 4.66$ seconds $)$ from those produced by inferior vena cava injections were noted.

Thus, this modified contrast agent is capable of opacifying the left ventricle after peripheral venous injection. The peripheral venous injection is just as effective as the inferior vena cava injection and causes no significant changes in blood pressure and heart rate.
\end{abstract}

\section{Introduction}

Opacification of left ventricle and myocardium after intravenous injection of echo contrast agent has been a goal of echocardiographers for many years
[1-4]. Meltzer and his colleagues [5] showed that microbubbles larger than $8 \mu \mathrm{m}$ in size are filtered by the 'sieve' action of the pulmonary capillary bed.

Efforts have been made to opacify the left ventri- 
cle after peripheral venous injection of several contrast agents [6-9]. Only limited papers have described the videodensity measurement, and the ratios of peak videodensity of left ventricle to that of right ventricle range from 0.28 to $0.35[8,10]$. Further studies to search for the ideal contrast agent that is stable, nontoxic, and capable of opacifying the left ventricle after intravenous injection are still needed. This study was undertaken to evaluate the effectiveness of a modified contrast agent - the combined albumin-glucose-glycerin solution - to opacify the left ventricle after peripheral venous injection in a canine model.

\section{Methods}

\section{Animal preparation}

Eight mongrel dogs weighing from 14 to 22 (mean 18.6) $\mathrm{kg}$ were anesthetized initially with intramuscular injection of Ketamin (10-13 mg/kg), then cannulated with an endotracheal tube and ventilated artificially with room air by a Harvard ventilation. The end expiratory $\mathrm{CO}_{2}$ concentration was maintained at $3.5-4.5 \%$. Anesthesia was maintained by intravenous injection of alpha-chloralose (30$10 \mathrm{mg} / \mathrm{kg}$ ) and urethane $(200-400 \mathrm{mg} / \mathrm{kg})$. A $6 \mathrm{~F}$ side-armed catheter was inserted into the femoral artery and connected to a multichannel recording system (Gould Interface 4600 and Gould ES 1000 recorder) for monitoring and recording the arterial pressure. The femoral vein was catheterized with a 6F side-armed sheath, followed by inserting a multi-hole pigtail catheter through the sheath to the inferior vena cava. A standard lead II electrocardiogram was also monitored continuously. Core temperature was maintained at $37^{\circ} \mathrm{C}$ by a heating pad.

A standard No. 19 jelco gauge was inserted into a left foreleg vein and connected to a short extension tube with stopcocks. The sonicated contrast agent was injected either through the stopcocks into peripheral vein or through the pigtail catheter into the inferior vena cava.

\section{Contrast agent preparation}

A Heat System sonicator (Model M-375) with a 0.5 inch $(1.27 \mathrm{~cm})$ diameter horn was used to generate microbubbles. The contrast solution was prepared by mixing the commercially available human albumin (produced by the Institute Merieux, Lyon, France), glucose, glycerin and distil water to make a $10 \mathrm{ml}$ solution containing $5 \%$ albumin, $50 \%$ glucose and $0.75 \mathrm{gm}$ glycerin. Usually $100 \mathrm{ml}$ mixed solution was made before the animal study. Fifty gm glucose powder was added in $50 \mathrm{ml}$ distil water, then heating and stirring till the sugar was dissolved in water. After it cooled down to room temperature, the albumin solution (equal to $5 \mathrm{gm}$ ) was added to the above solution followed by adding distil water to make a $100 \mathrm{ml}$ solution. Before solication, $0.75 \mathrm{gm}$ glycerin solution $(=0.6 \mathrm{ml})$ was added in each $10 \mathrm{ml}$ mixed albumin and glucose solution. Ten $\mathrm{ml}$ of this combined albumin-glucose-glycerin solution was sonicated for 70 seconds with introduction of the tip of the sonicated horn into the solution similar to the technique described previously [11, 12].

After sonication, one drop solution was sampled from the middle layer and promptly placed on a microscope slide covered with a coverslip. The images of microbubbles in different fields were recorded in high quality videotape via videocamera and played back subsequently for analysis. The microbubble diameter was measured for at least 4 consecutive fields with the assistance of micrometer (Nikon, MBM 11100). Totally 200 microbubbles were measured and the mean value was calculated. The diameter of 100 red blood cell from a blood smear of a normal subject was also measured and mean value was determined for comparison (Fig. 1).

\section{Study protocol}

Multiple hand injections of $8 \mathrm{ml}$ sonicated contrast solution through the extension tube and the jelco gauge into foreleg vein, and through the pigtail catheter into the inferior vena cava were performed. Each injection was followed by a rapid flush 


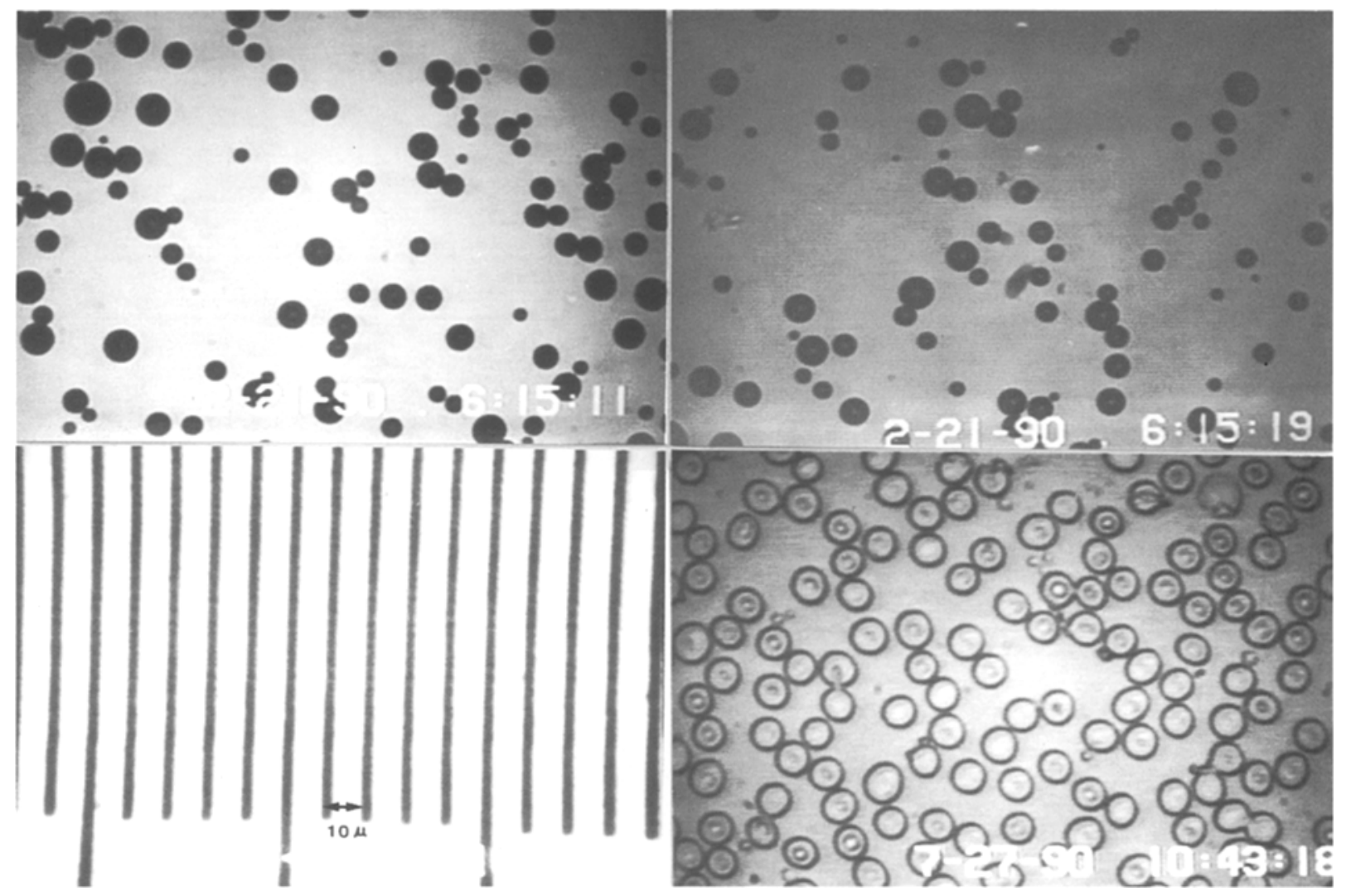

Fig. l. Showing the microscopic images $(\times 400)$ of microbubbles (upper panels), the micrometer (lower left) and the red blood cells of a normal subject (lower right panel).

with $10 \mathrm{ml}$ normal saline solution. The electrocardiogram, blood pressure and heart rate were continuously monitored.

\section{Echocardiographic study}

Two-dimensional echocardiogram was performed by using an Irex-Meridian Echo machine with a 2.5 MHz transducer. The dog was placed on a special table with a cutout region corresponding to the dog heart area. The modified long axis view was obtained at the right lateral decubitus position from a closed chest dog. The two-dimensional echocardiograms were first adjusted for optimal resolution and for good imaging quality during the baseline study. Once the gain setting was established, the total-gain, rejection, depth, transmit power and the time-gain compensation were kept constant thereafter throughout the study in each dog. All contrast injections were recorded on a high quality FUJI (VHS) videotapes for subsequent play back and off-line computer analysis.

\section{Videodensitometric analysis}

Echocardiograms were analyzed off-line by using an image digitizing system developed in our laboratory [13]. This system has a multifunctioning Panasonic model AG-6300 VHS videocassette recorder, a high resolution Barco color monitor with R-G-B signal output, a Time Base Corrector and a computer system. The computer system can digitize a full field of analog video data with a resolution of $512 \times 512$ picture elements (pixels) by 256 


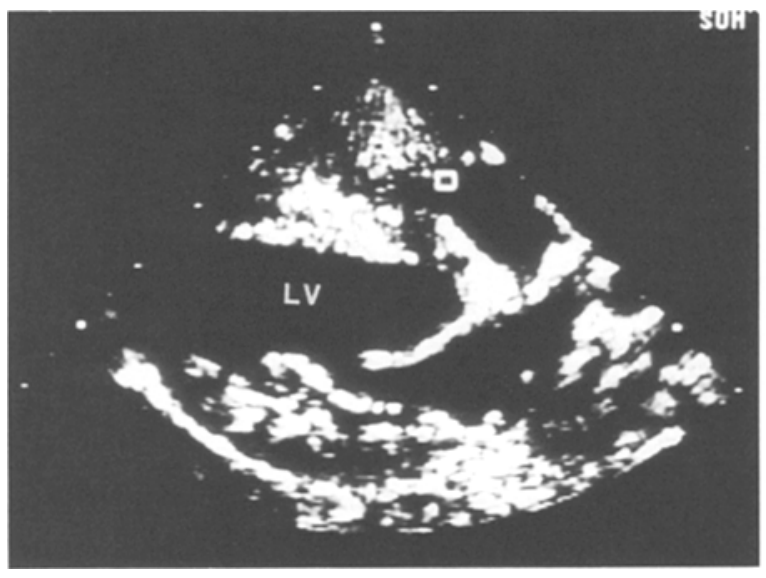

VIDEODENSITY OF RIGHT VENTAICLE AFTER BACKGROUND SUBTRACTION

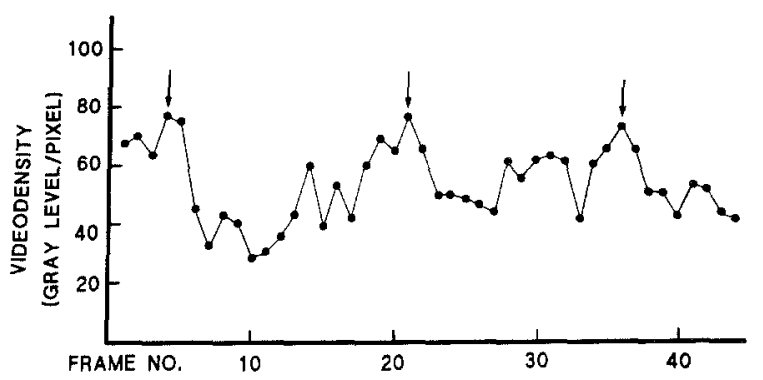

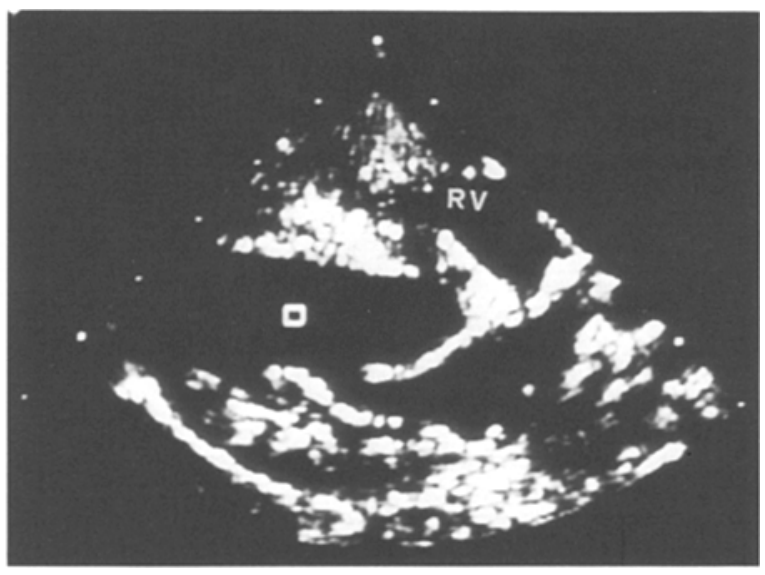

VIDEODENSITY OF LEFT VENTRICLE AFTER BACKGROUND SUETRACTION

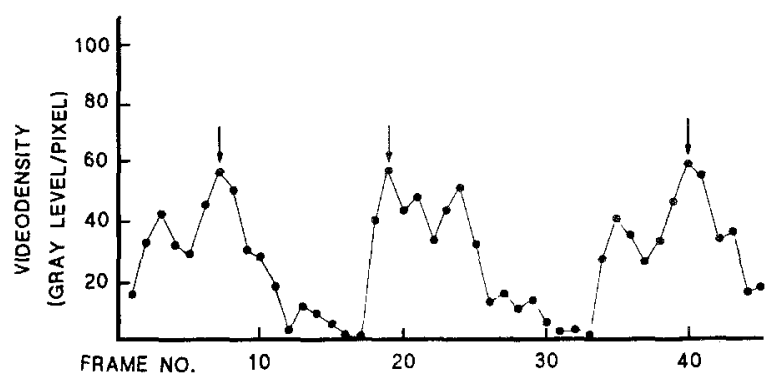

Fig. 2. Selecting of a region of interest (the rectangle area in the center of right (left upper) and left (right upper) ventricle and the videodensity curve of both ventricles (lower) for 3 consecutive cardiac cycles. The videodensity curve from right and left ventricle was not measured simultaneously. The LV contrast enhancement occurred in diastole and arrows indicated the peak videodensity of each cardiac cycle, the videodensity tended to decrease in systole (asterisks). $R V=$ right ventricle, $L V=$ left ventricle. (see text).

gray levels. The videodensity of the same region of interest at the center of right ventricle and left ventricle avoiding the cardiac structures such as endocardium, valvular leaflets and chordae was determined by this image digitizing system. The background videodensity of right ventricle and left ventricle was evaluated in 10 frames and the mean gray level was obtained. The videodensity over the same regions at the center of both ventricles were measured in all frames for 3 consecutive cardiac cycles (the cardiac cycle with peak ventricular contrast enhancement and the preceding and following cycles). Figure 2 demonstrated the selection of a region of interest in the center of right and left ventricle and the videodensity of both ventricles for 3 cardiac cycles. The peak videodensity (arrow) of each cardiac cycle was determined and the mean value was calculated. The peak videodensity of right and left ventricle subtracting the background videodensity of both ventricles were obtained respectively. The ratio of peak videodensity of left ventricle to that of right ventricle was further calculated in each injection. The number of pixels within the region of interest was 64 pixels throughout the study. Since excessive right ventricular echo with lateral shadowing (Fig. 3) occurred usually in the $2-3$ cardiac cycles at the beginning of contrast echo appearing in the right ventricle which may affect the videodensity measurement, these frames were therefore excluded. Only the cardiac cycles with peak right ventricular contrast without shadowing were selected for study. 


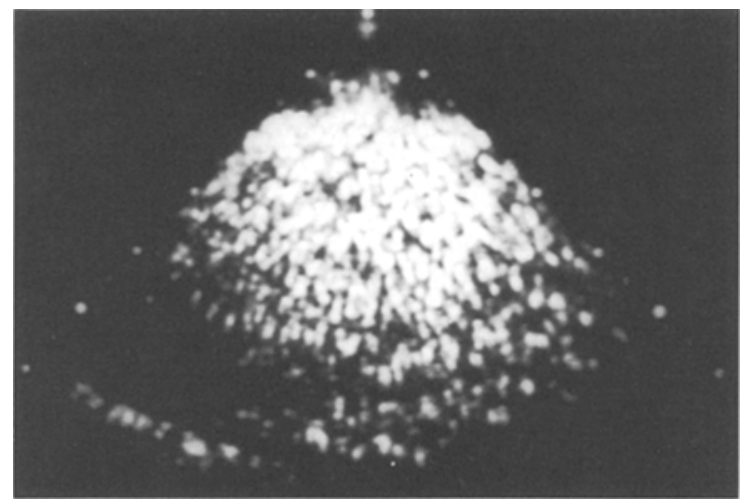

Fig. 3. Showing the excessive right ventricular echo with substantiate shadowing which may affect the measurement of videodensity of right ventricle.

The left ventricular contrast persistent time was defined as the total time in seconds during which contrast was detectable within the region of interest in left ventricle, from the appearance of contrast to the point at which the videodensity closed to the baseline intensity.

Pulmonary transit time (in seconds) was defined as the time from the arrival of contrast echo in the right ventricle to that in the left ventricle.

\section{Statistical analysis}

The Wilcoxon rank sum test was used to compare videodensity, pulmonary transit time and left ventricular persistent time from peripheral vein versus inferior vena cava injections. Statistical significance is defined as $\mathrm{p}<0.05$.

\section{Results}

\section{Microbubble diameter}

The microbubble diameter ranged from 1 to 9 (mean 5.0 \pm 2.3 ) $\mu \mathrm{m}$. The diameter of red blood cells ranged from 6 to 9 (mean $7.1 \pm 0.9$ ) $\mu \mathrm{m}$.

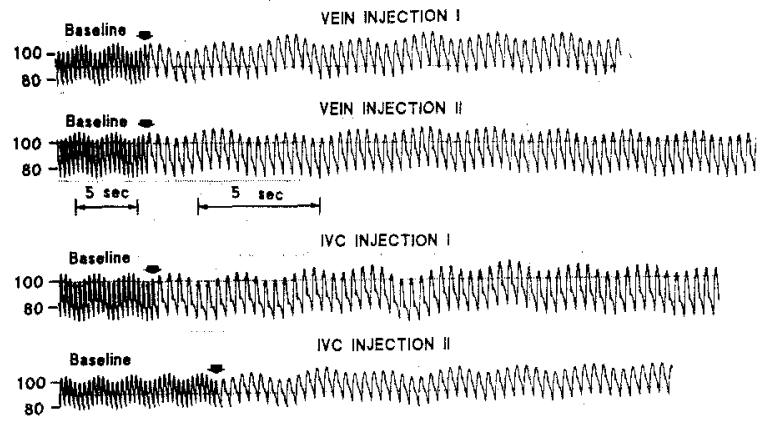

Fig. 4. Depicting the blood pressure recording from peripheral venous (upper) and inferior vena cava injections (lower). Slight variation of baseline blood pressure due to respiration was noted. Contrast agent injections (arrows) caused slight but insignificant increase in blood pressure but soon returned to baseline level.

\section{Side effects}

All dogs tolerated the peripheral venous and inferior vena cava injections of this contrast agent. No arrhythmia or ST-T change of the electrocardiogram and no significant change in heart rate were noted before versus after injection of the contrast agent. Slight increase in blood pressure after injection but soon returned to baseline were noted in all dogs (Fig. 4). The increased systolic blood pressure $(112.7 \pm 9.5 \mathrm{mmHg})$ was statistical-

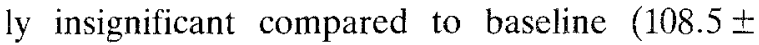
$9.4 \mathrm{mmHg}$ ). The echocardiograms revealed no regional wall motion abnormalities throughout the study.

\section{Right ventricular and left ventricular contrast}

All injections produced contrast echo in right ventricle. Excessive right ventricular echo in the initial 2-3 cardiac cycles after injections might result in substantiate shadowing which was observed in all injections. Figure 5 demonstrated the echocardiograms in a dog before- (upper) and after-injection of this modified albumin solution with contrast enhancement in the right ventricle (middle) and left ventricle (lower). Dense echo contrast in left ventricle was noted which indicating a great amount of contrast agent had transmitted through the lungs. 

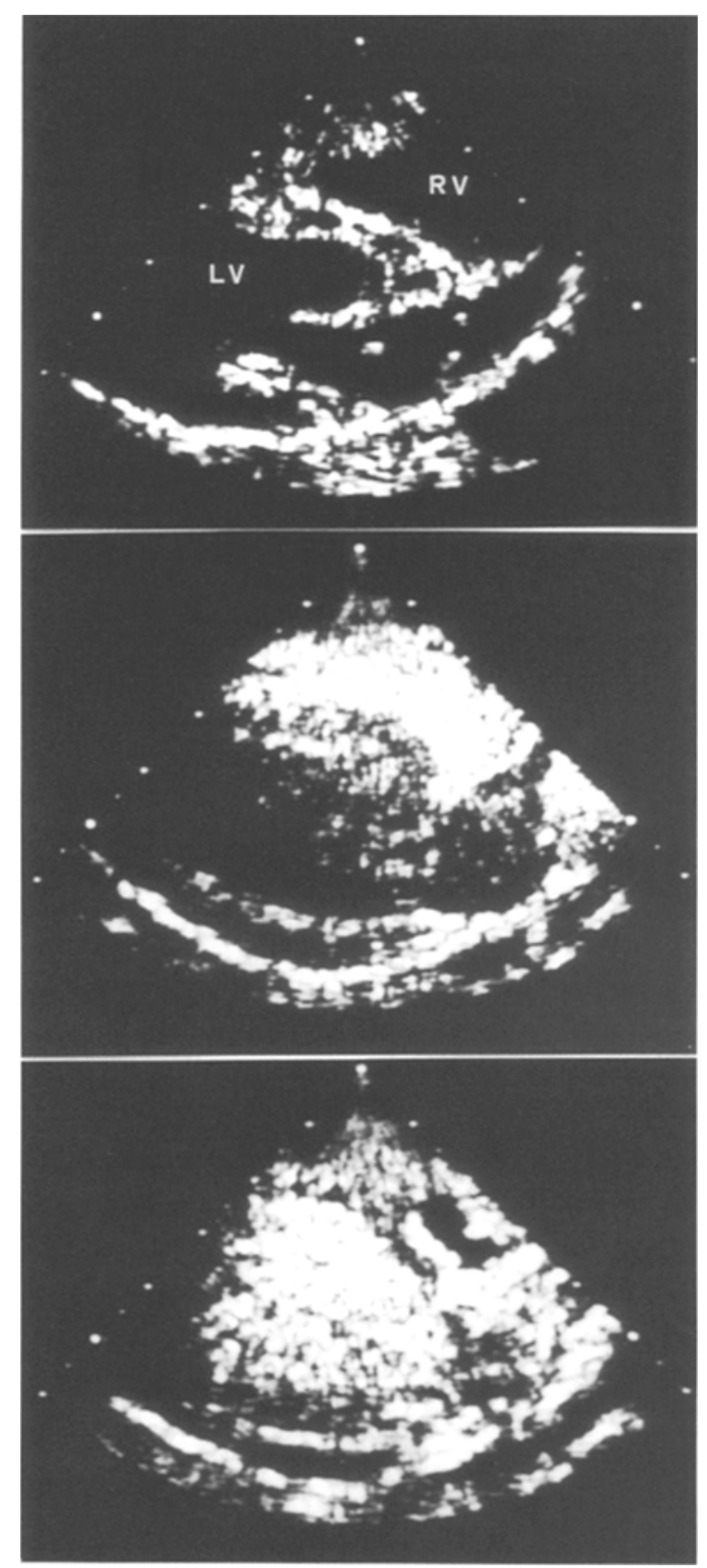

Fig. 5. Showing the echocardiograms of a modified long axis view in a dog before injection of echo contrast agent (upper), the contrast enhancement in right ventricle (middle) and left ventricle (lower). Dense echo contrast appearing in both ventricles could be observed. $\mathrm{RV}=$ right ventricle, $\mathrm{LV}=$ left ventricle.
In peripheral venous injection, the mean right ventricular and left ventricular background videodensity was $0.63 \pm 0.35$ and $0.13 \pm 0.16$ gray level/ pixel respectively. In the left ventricular videodensity curve, the peak videodensity occurred not only in early diastole but also in atrial systole. In Fig. 2, there were two top points in each cardiac cycle of the videodensity curve, in the first and third cycle, the peak occurred at atrial systole, while in the middle cycle it occurred at early diastole. Meanwhile, the videodensity tended to decrease in systole.

After subtracting the background videodensity, the mean peak right ventricular videodensity was $78.4 \pm 11.1$ gray level/pixel. Thirty-four $(85 \%)$ of the 40 intravenous injections resulted in left ventricular contrast with a mean peak left ventricular videodensity of $55.6 \pm 10.73$ gray level/pixel. The ratio of peak left ventricular videodensity to peak right ventricular videodensity ( $\mathrm{LV} / \mathrm{RV}$ ) in individual injection ranged from 0.42 to 0.90 (mean $0.68 \pm 0.15$ ). Similarly, after subtracting the baseline videodensity, the inferior vena cava injection produced left ventricular contrast with a mean peak right ventricular videodensity of $81.22 \pm$ 12.24 gray level/pixel. The peak left ventricular videodensity was $56.04 \pm 11.68$ gray level/pixel which is $65 \%$ as bright as that from the right ventricle (Fig. 6).

\section{Pulmonary transit time and left ventricular persistent time}

In peripheral venous injection, the pulmonary transit time ranged from 2.83 to 4.48 (mean $4.05 \pm$ $0.53)$ and the left ventricular contrast persistent time ranged from 12.0 to 14.5 (mean $13.67 \pm 4.28$ ). There were no difference of the pulmonary transit time $(3.93 \pm 0.47, P=N . S)$, and left ventricular contrast persistent time $(11.65 \pm 4.66, \mathrm{P}=\mathrm{N}$.S $)$ as compared with those injected from inferior vena cava. 


\section{Discussion}

Sonicated albumin solution has been previously evaluated as an echocardiographic contrast agent $[6,14,15]$. It has been shown that sonicated albumin did not alter hemodynamic, coronary blood flow or left ventricular contractility [14]. We have added glycerin in the albumin solution, as glycerin is a demulcent polyhydroxy compound which is miscible with water and alcohol. It has been extensively employed as a vehicle for many drugs such as those used for the treatment of cerebral edema, to lower occular tension in glaucoma, or as a lotion for roughened skin [16]. The glycerin added to the albumin solution may be helpful to produce microbubbles which are smaller in size and more stable. Although glycerin by itself does not function as bubbling agent, it contributes to the prohibition of bubble fusion, so it can stabilize small-size microbubble. Meanwhile, as intravenous injection of glycerin has been used to treat some diseases, it was selected because it may cause nontoxic and less side effect. The goal of high concentration glucose seems to increase viscosity of the albumin solution so that higher temperature can be reached during sonication. This would assist in the denaturation of albumin into the surface active form, which in turns can stabilize the bubbles. It seemed that the microbubbles derived from this contrast agent had a satisfactory size which comparable to the size of red blood cells, can be transferred from pulmonary circulation smoothly without prolongation of pulmonary transit time. Previous reports described that intracoronary sonicated albumin $[11,18]$ and intravenous Albunex [9] produced no significant side effects and increased dosage of Albunex (up to $0.12 \mathrm{ml} / \mathrm{kg}$ ) was well tolerated. Our study found that there was no significant change in the electrocardiograms, blood pressure and heart rate during and after the hand injection of this modefied albumine solution.

The peak intensity of right and left ventricle produced by contrast echo was obtained with the peak videodensity minus the baseline videodensity. Since both ventricles might have different depth from the transducer and different gain control settings, they might have different background video-
PEAK VIDEODENSITY OF BOTH VENTRICLES

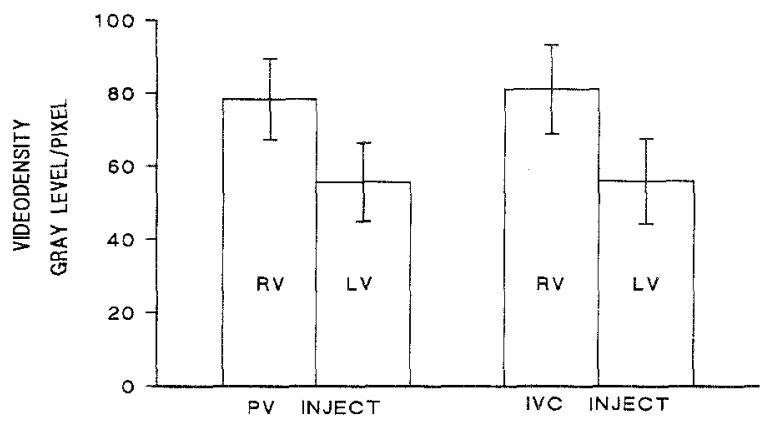

Fig. 6. Depicting the bar diagrams of peak videodensity of both ventricles in peripheral venous (PV) injection and inferior vena cava (IVC) injection. $R V=$ right ventricle, $L V=$ left ventricle.

density. We found that the background videodensity of right ventricle tended to be greater than that of left ventricle (Table 1). The ratio of the videodensity of left ventricle to that of the right ventricle was considered to be comparable only if it was corrected after subtracting the background videodensity. This ratio reflected the amount of contrast agent passage through lungs to the left ventricle. As only the videodensity with peak ventricular contrast enhancement in right and left ventricle was measured, the cardiac cycles selected for the videodensity measurement in right ventricle were usually earlier than those in left ventricle and they were not in the same cardiac cycles. We noticed that the left ventricle contrast enhancement occurred not only in early diastole but also in atrial systole, while it tended to decrease in systole (Fig. 2). Similar finding of systolic decrease in left ventricular contrast intensity have been reported by Shapiro et al. This phenomenon was considered probably due to the destruction of albumin-coated microbubbles by high left ventricular systolic pressure [10]. Two other factors might also affect the videodensity measurement. First, the dog was on assist ventilation during echo study. Although we tried to fix the transducer at the same position throughout the study, yet, the transducer position still possible to have small changes during respiration. Slight change of transducer position would affect the videodensity measurement considerably. It was the limitation that we could not get rid of it 
completely. Second, since the size of each ventricle might change at different phase of cardiac cycle, therefore, it was hard to place the region of interest at the center of both ventricles with changing size. The selection of the region of interest possibly might contribute to the variability in the videodensity measurement.

A wide variability in the efficacy of transpulmonary passage of contrast agent and a significant decrease in left ventricular contrast intensity as compared with right ventricular intensity had been observed by the peripheral venous injection of the sonicated albumin [10]. Keller and his colleagues also noted a transpulmonary lose of $61 \%$ of the contrast effect after intravenous injection of sonicated albumin in dogs. In our 80 injections, all peripheral venous injections and inferior vena cava injections resulted in right heart contrast echo. Eighty-five percent of the peripheral venous injections and $82.5 \%$ of the inferior vena cava injections resulted in left ventricular contrast enhancement. While other injections produced only faint visualization of left ventricle in some dogs. Since we did not routinely examine the physical condition of our dogs, these animals had different weight, species and gender. Besides, we did not know whether these dogs might have parasites in the lung tissue or they might have minor pulmonary disease, these factors could play some roles to influence the left ventricular opacification. We felt that both peripheral venous and inferior vena cava injection of this contrast agent can produce efficient left ventricular opacification and the echo intensity was $68 \%$ and $65 \%$ of that produced in the right ventricle. These results showed that the modified albumin solution had a relatively greater rate of left ventricular opacification and possibly more denser of the left ventricular echo intensity than those reported previously. This difference may be due to the difference in contrast agent, in dogs or in different method of measurement of peak echo intensity.

\section{Conclusion}

This study has demonstrated that good results of left ventricular opacification can be produced by this modified albumin solution after peripheral venous injection and caused no significant changes in blood pressure and heart rate. The peripheral venous injection is just as effective as inferior vena cava injection in the left ventricular opacification and, therefore, the peripheral vein as an injecting site is recommended. Further study to evaluate the usefulness of this contrast agent to opacify the left ventricle in human is needed.

\section{Acknowledgement}

We thank Mr. Chien-Yu Wang for technical assistance and Miss Fu-Rong Chang for typing the manuscript. Presented in part at the 63rd Scientific Session of the American Heart Association Meeting at Dallas, Texas, 1990. This study is supported by National Science Council, Taipei, Taiwan, R.O.C., Grant No. NSC80-0412-B075-89.

Table 1. Data after injection of contrast agent.

\begin{tabular}{lcc}
\hline & PV injection & IVC injection \\
\hline Pulmonary transit time (second) & $4.05 \pm 0.53$ & $3.93 \pm 0.47$ \\
LV contrast persistent time (second) & $13.67 \pm 4.28$ & $11.65 \pm 4.66$ \\
RV background videodensity & $0.63 \pm 0.35$ & $1.0 \pm 0.90$ \\
LV background videodensity & $0.13 \pm 0.16$ & $0.13 \pm 0.18$ \\
RV peak videodensity & $78.40 \pm 11.10$ & $81.22 \pm 12.24$ \\
LV peak videodensity & $55.66 \pm 10.73$ & $56.04 \pm 11.68$ \\
LV/RL videodensity ratio & $0.68 \pm 0.15$ & $0.65 \pm 0.18$
\end{tabular}

$\mathrm{RV}=$ right ventricle, $\mathrm{LV}=$ left ventricle, $\mathrm{PV}=$ peripheral vein, $\mathrm{IVC}=$ inferior vena cava, videodensity unit $=$ gray level $/ \mathrm{pixel}, \mathrm{P}=$ no significance in all comparisons of PV versus IVC injection. 


\section{References}

1. Reale A, Pizzuto F, Gioffre PA, et al. Contrast echocardiography: transmission of echoes to the left heart across the pulmonary vascular bed. Eur Heart J 1980; 1: 101-6.

2. Meltzer RS, Tickner EG, Shaines TP, Popp RL. Transmission of echocardiographic contrast through the lung. Ultrasound Med Biol 1981; 7: 377-84.

3. Valdes-Cruz LM, Shan DJ. Ultrasonic contrast studies for the detection of cardiac shunts. J Am Coll Cardiol 1984; 3 : 978-85.

4. Meltzer RS, Serruys PW, McGhie J, Verbaan N, Roelandt J. Pulmonary wedge injection yielding left-side echocardiographic contrast. Br Heart J 1980; 44: 390-4.

5. Meltzer RS, Tickner EG, Popp RL. Why do the lung clear ultrasonic contrast? Ultrasound Med Biol 1980; 6: 263-9.

6. Keller MW, Feinstein SB, Watson DD. Successful left ventricular opacification following peripheral venous injection of sonicated contrast agent: an experimental evaluation. Am Heart J 1987; 114: 570-5.

7. Berwing K, Schlepper M. Echocardiographic imaging of the left ventricle by peripheral intravenous injection of echo contrast agent. Am Heart J 1988; 115: 399-408.

8. Smith MD, Elion JL, McClure RR, Kwan OL, DeMaria AN. Left heart opacification with peripheral venous injection of a new saccharide echo contrast agent in dogs. $\mathrm{J}$ Am Coll Cardiol 1989; 13: 1622-8.

9. Feinstein SB, Cheirit J, Ten Cate FJ, Silverman PR, Heidenrich PA, Dick C, Desir RM, Amstrong WF, Quinones MA, Shah PM. Safety and Efficacy of a new transpulmonary ultrasound contrast agent: initial multicenter clinical results. J Am Coll Cardiol 1990; 316-24.

10. Sharpiro JR, Reisner SA, Lichtenberg GS. Intravenous contrast echocardiography with use of a sonicated albumin in humans: systolic disappearance of left ventricular contrast after transpulmonary transmission. J Am Coll Cardial 1990; 16: 1603-7.

11. Reisner SA, Ong LS, Lichtenberg GS, et al. Myocardial perfusion imaging by contrast echocardiography with use of intracoronary sonicated albumin in humans. J Am Coll Cardiol 1989; 14: 660-5.
12. Feinstein SB, Ten Cate FJ, Zwehl W, et al. Two-dimensional echocardiography. I. In vitro development and quantitative analysis of echo control agents. J Am Coll Cardiol 1984; 3: 14-20.

13. Lin SL, Liu RH, Leu FJ, Shih JM, I MK, Kuo JS, Tai DY, Chang MS, Wang SP, Chiang BN. Detection of acute canine myocardial ischemia by analysis of two-dimensional echocardiographic gray level. Acta Cardiol Sin 1990; 6: $180-90$.

14. Keller MW, Glasheen W, Teja K, Gear A, Kaul S. Myocardial contrast echocardiography without significant hemodynamic effect or reactive hyperemia: a major advantage in the imaging of regional myocardial perfusion. J Am Coll Cardiol 1988; 12: 1039-47.

15. Feinstein SB, Heidenreich PA, Dick CD, et al. Albunex: a new intravascular ultrasound contrast agent: preliminary safety and efficacy results [abstract]. Circulation 1988; 78 Suppl II: II A-565A.

16. Swinyard EA, Pathak MA. Surface-acting drugs. In: Gilman AG, Goodman LS, Rall TW, Murad F. 7th Ed. Goodman and Gilman's The pharmacological Basis of Therapeutics. New York: MacMillan Publishing Company 1985: 946-58.

17. Dick CD, Heidenrich P, Aronson S, Gluck D, Tamler B, Feinstein SB. Reproducible myocardial perfusion with intravenous contrast echocardiography [abstract]. Circulation 1988: 78 Suppl II: IIA-565A.

18. Reisner SA, Ong LS, Fitzpartrick PG, et al. Evaluation of coronary flow reserve by quantitative myocardial contrast echo [abstract]. Circulation 1989; 80 Suppl II: IIA-370A.

Address for offprints:

Shoa-Lin. Lin, M.D.

Division of Cardiology,

Department of Internal Medicine,

Veterans General Hospital-Kaohsiung,

No. 386 Dar-Chung 1st Road,

Kaohsiung City,

Taiwan 80780, R.O.C. 